\section{A Delayed Presentation of Right Main Bronchus Disruption with Chylothorax}

\section{Sir,}

Blunt chest trauma leading to tracheobronchial injury (TBI) is not very common. TBI occurs in $0.2 \%$ to $0.8 \%$ of patients of blunt chest trauma. ${ }^{1-3}$ Mild injuries are often missed; and patients with severe injuries often die before reaching the hospital. Within 24 hours of injury, percentage of such cases diagnosed was only $30 \% .{ }^{4} \mathrm{~A}$ delay in diagnosis and repair of airway leads to fatal complications. Usually, pulmonary collapse and sepsis have already occurred when the injury is diagnosed. We present a case of TBI, which was diagnosed three weeks after the injury.

A man, aged 30 years, presented with 16-day history of road traffic accident (RTA). The delayed referral from a low resource hospital was because of unwillingness of the patient for referral to the tertiary care hospital. He had RTA 16 days back and got his ribs fractured on right side of the chest with surgical emphysema and pneumothorax. He developed respiratory failure for which he was kept on ventilator. After the patient weaned off, he remained on oxygen support having persistent pneumothorax and surgical emphysema. He was shifted to Combined Military Hospital, Lahore two weeks after initial injury. He had chest intubation which showed milky fluid and persistent air leak. X-ray chest showed partial lung expansion. Chest CT and 3D reconstruction and bronchoscopy were carried out, which showed complete transection of right main bronchus (Figure 1). Pleural fluid examination showed chyle. Triglyceride levels were more than $140 \mathrm{mg} / \mathrm{dl}$. Right-sided posterolateral thoracotomy was performed, 20 days after the initial injury. Decortication, and repair of right main bronchus was performed followed by enmass ligation of thoracic duct in a single sitting. Both ends of transected bronchus were debrided (Figure 2a). End-to-end anastosmosis with vicyl $3 / 4.0$ was done with interrupted stitches and knots on outside (Figure 2 b,c). Intercostal mucle flap (ICM) was buttressed to the anastomosis. Supra-diaphragmatic enmass ligation of thoracic duct was done. Air leak was checked and the peroperative lung expansion was satisfactory (Figure 2d). Post-operative lung expansion was satisfactory clinically (Figure 3c). Postoperative recovery was uneventful. Postoperative bronchoscopy at third week follow-up showed no bronchial stenosis (Figure $3 b$ ).

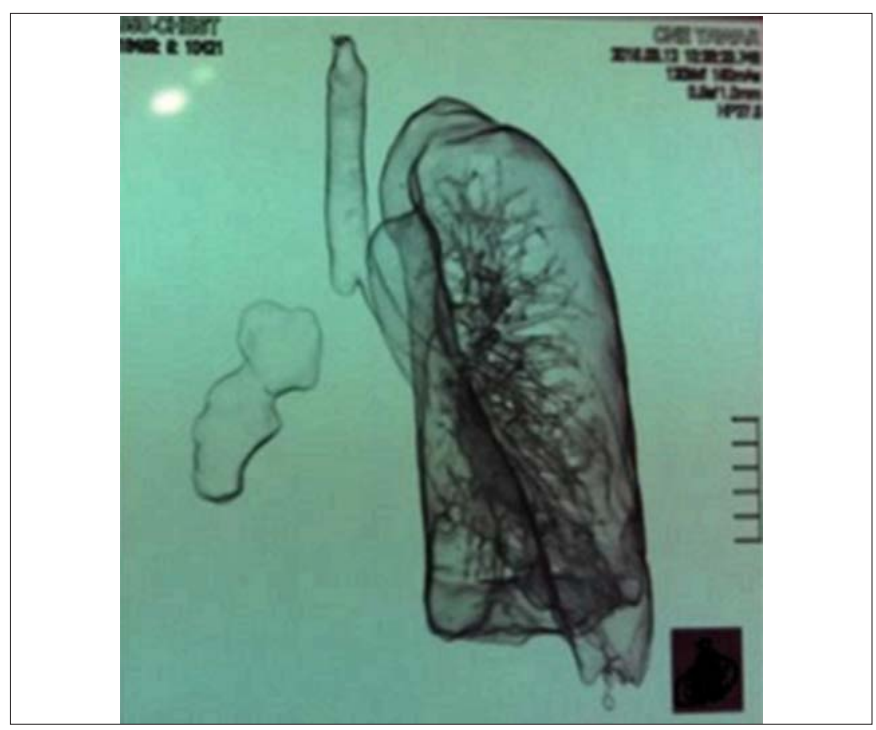

Figure 1: CT scan showing the transaction of right main bronchus.

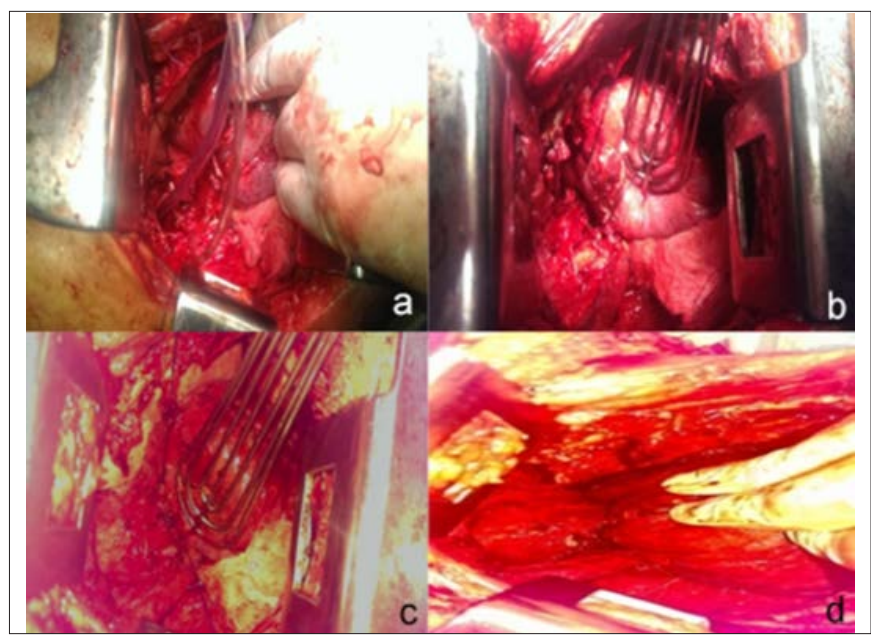

Figure 2: (a) Open ends of the right main bronchus.(b) Posterior wall of the right bronchus repaired. (c) Anterior wall of the right bronchus repaired. (d) Lung expanded postoperatively.

According to a study on TBI, majority of cases were due to RTA. ${ }^{3}$ This case also resulted from an RTA. TBI is fatal to life. Due to sudden compression of chest in a patient with closed glottis, the pressure in the lumen of trachea increases and the membranous part of the trachea gets ruptured leading to tear of carina. Within $2.5 \mathrm{~cm}$ of the carina, the percentage of tracheobronchial ruptures is more than $80 \% .4$ In this case, injury also occurred within $2.5 \mathrm{~cm}$ of carina. When pneumomediastinum and pneumothorax are found together, which are noncompliant to tube thoracostomy, chances of such injuries is raised. ${ }^{5}$ Delay in the diagnosis of bronchial disruption leads to stricture formation with secondary atelectasis or bronchiectasis of distal lung. 6 However, there was no stricture formed in this patient. Bronchoscopy is required to confirm the injury when 


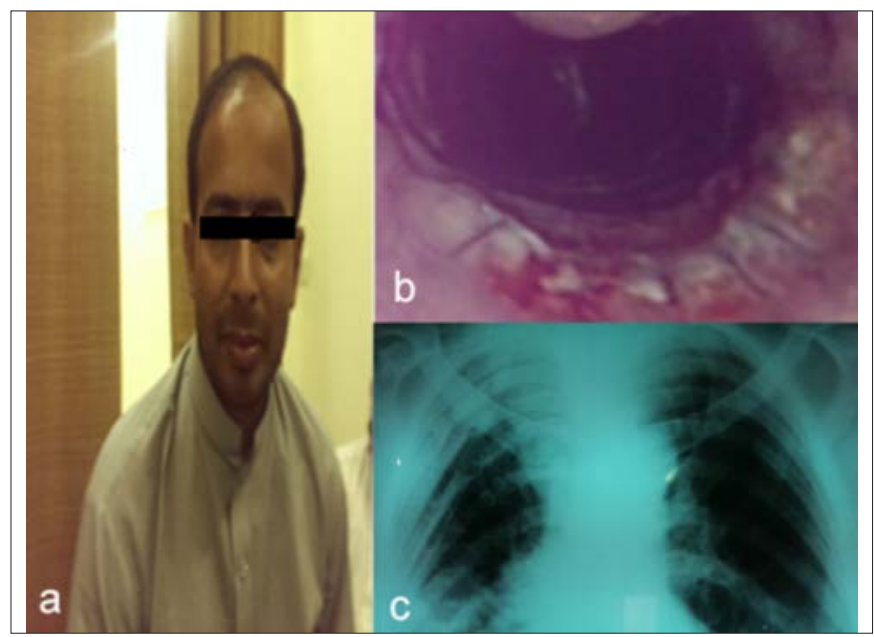

Figure 3: (a) Patient on follow-up visit with normal breathing. (b) Bronchoscope on follow-up visit showing adequate anastomosis with no knots inside and no broncho-stenosis. (c) Post-op X-ray showing expanded lung.

disruption is found on 3D CT reconstruction. 4 We also confirmed this injury by bronchoscopy after 3D reconstruction of tracheobronchial tree. Site of injury can be exposed by posterolateral thoracotomy. After debriding traumatic margins, primary repair was done with interrupted absorbable sutures. ICM flap was also applied. This patient had a successful repair even after a delayed diagnosis. In a case report by Baumgartner et al., chylothorax occurred in a patient along with right main bronchus disruption due to blunt trauma of chest and was treated conservatively. ${ }^{3}$ In our case, we did supra-diaphragmatic ligation of thoracic duct.

In conclusion, the case highlights the need to keep in mind the TBI in cases of blunt trauma to the chest, especially those caused by RTA.

\section{CONFLICT OF INTEREST:}

Authors declared no conflict of interest.

\section{AUTHORS' CONTRIBUTION:}

FAM: Menuscript writing, data collection.

UZ: Provided figures, data analysis.

UM: Provided figures.

\section{REFERENCES}

1. Barmada $\mathrm{H}$, Gibbons JR. Tracheobronchial injury in blunt and penetrating chest trauma. Chest 1994; 106; 74-18.

2. Battistella FD, Benfield JR. Blunt and penetrating injuries of the chest wall, pleura and lungs. General thoracic surgery, $5^{\text {th }}$ ed. Philadelphia: Lippincott Williams \& Wilkins, 2000; 815-31.

3. Baumgartner F, Sheppard B, de Virgilio C, Esrig B, Harrier D, Nelson RJ, et al. Tracheal and main bronchial disruptions after blunt chest trauma: Presentation and management. Ann Thorac Surg 1990; 50:569-74.

4. Shields TW, Locicerolll J. Blunt and penetrating injuries of the chest wall, pleura and lungs. General thoracic surgery. 2009; Philadelphia: Lippincott Williams \& Wilkins, $7^{\text {th }}$ edition. pp. 891902.

5. Cheaito A, Tillou A, Lewis C, Cryer H. Traumatic bronchial injury. Int J Surg Case Rep 2016; 28:26-30.

6. Ozcelik C, Onat S, Bayar ES. Combined late diagnosed right main bronchial disruption and chylothorax from blunt chest trauma. Ann Thorac Surg 2004; 78:e61-2.

Farhan Ahmed Majeed', Usama Zafarl and Umer Mehmood ${ }^{2}$

1 Department of Thoracic Surgery, Combined Military Hospital, Multan, Pakistan

2 Department of Surgery, Combined Military Hospital, Lahore, Pakistan

Correspondence to: Dr. Usama Zafar, Combined Military

Hospital, Multan, Pakistan

E-mail: usamazafar0705@gmail.com

Received: October 25, 2018; Revised: June 27, 2019

Accepted: June 27, 2019 